\title{
PENGARUH KUALITAS PELAYANAN TERHADAP KEPUASAN DAN LOYALITAS PENGUNJUNG DALAM MENGGUNAKAN JASA HOTEL RIZEN KEDATON BOGOR
}

\author{
Nurmin Arianto \\ email : nurmin1989@gmail.com
}

\begin{abstract}
ABSTRAK
Penelitian ini bertujuan untuk 1) mengetahui pengaruh kuliatas pelayanan terhadap kepuasan pengunjung, 2) mengetahui kualitas pelayanan terhadap loyalitas pengunjung.3) mengetahui kepuasan pengunjung terhadap loyalitas pengunjung.

Poulasi dalam penelitian ini adalah Tamu yang berkunjung ke Hotel dari Bulan Januari sampai dengan Agustus 2016 yaitu sebanyak 17.457 diperkecil dengan menggunakan rumus slovin dengan error $10 \%$ menjadi 100 pengunjung. Teknik pengumpulan data menggunakan kuisioner sedangkan teknik analisis data menggunakan analisi regresi linier sederhana.

Dari hasil penelitian bahwa terdapat pengaruh yang positif dan signifikan antara kualitas pelayanan terhadap kepuasan pengunjung dan loyalitas pengunjung serta terdapat pengaruh yang positif dan signifikan antara kepuasan pengunjung terhadap loyalitas pengunjung.
\end{abstract}

Kata kunci :Loyalitas pengunjung, kepuasan pengunjung, kualitas pelayanan.

\section{ABSTRACT}

This study aims to 1) determine the effect of the quality of service to visitor satisfaction, 2) determine the quality of service to visitor loyalty. 3) determine the satisfaction of visitors to visitor loyalty.

The population in this study is the Guests who visit the Hotel from January until August 2016 as many as 17.457 be minimized by using the slovin formula with an error of $10 \%$ to 100 visitors. Data collection techniques using the questionnaire while the technique of data analysis using analysis of simple linear regression.

From the research that there are positive influence and significant between quality of service to visitor satisfaction and visitor loyalty as well as there is a positive and significant influence between the satisfaction of visitors to visitor loyalty.

\section{Keywords : Visitor Loyalty, Visitor Satisfaction, Service Quality.}

\section{A. Pendahuluan}

Kualitas pelayanan berpusat pada pemenuhan kebutuhan dan keinginan serta ketepatan penyampaian untuk mengimbangi harapan pelanggan.Pelayanan disini adalah segala macam bentuk pelayanan yang diberikan oleh pihak hotel selama para tamu atau konsumen tersebut berada di hotel, meliputi pelayanan yang di berikan oleh receptionist, bell boy, room service, security, cleaning service, dll. Hal ini sesuai dengan pengertian Kotler dalam Lupiyoadi (2014:7) "kualitas pelayanan adalah setiap tindakan atau kegiatan yang dapat ditawarkan oleh satu pihak kepada pihak lain, pada dasarnya tidak berwujud dan tidak mengakibatkan perpindahan kepemilikan apapun. Produksi jasa mungkin berkaitan dengan produk fisik atau tidak.

Hotel Rizen Kedaton adalah hotel yang berdomisili di jalan Lodaya Desa Bojong Honje, Sukaraja Gunung Geulis, Jawa Barat.Jumlah tamu yang 
berkunjung di Hotel Rizen Kedaton sampai dengan tahun 2016 sebagai berikut:

Tabel 1.1

Tabel Pertumbuhan Jumlah Tamu Menginap di Hotel Rizen Kedaton Jawa Barat Tahun Jan 2016 - Jan 2017

\begin{tabular}{|c|c|c|c|c|c|c|c|}
\hline Tahun & Bulan & $\begin{array}{c}\text { Jumlah } \\
\text { Kamar } \\
\text { Terjual }\end{array}$ & $\begin{array}{c}\text { Jumlah } \\
\text { Tamu } \\
\text { Datang }\end{array}$ & Tahun & Bulan & $\begin{array}{c}\text { Jumlah } \\
\text { Kamar } \\
\text { Terjual }\end{array}$ & $\begin{array}{c}\text { Jumlah } \\
\text { Tamu } \\
\text { Datang }\end{array}$ \\
\hline 2016 & Jan & 515 & 1450 & 2016 & Juli & 247 & 847 \\
\hline 2016 & Feb & 1118 & 1423 & 2016 & Agus & 421 & 1187 \\
\hline 2016 & Mar & 907 & 1204 & 2016 & Sept & 531 & 1011 \\
\hline 2016 & Apr & 579 & 1427 & 2016 & Okt & 1241 & 1754 \\
\hline 2016 & Mei & 1093 & 1378 & 2016 & Nov & 1199 & 1617 \\
\hline 2016 & Juni & 326 & 860 & 2016 & Des & 1567 & 1832 \\
\hline \multicolumn{7}{|c|}{ Total kamar Terjual } \\
\hline \multicolumn{7}{|c|}{ Total Tamu Datang } \\
\hline \multicolumn{7}{|c|}{} \\
\hline \multicolumn{7}{|c|}{}
\end{tabular}

Sumber : Data Kunjungan Tamu Risen Kedaton, Jan 2016-Des 2016

Berdasarkan Tabel 1.1 diatas, tingkat kunjungan tamu yang menginap di Hotel Rizen Kedaton mengalami fluktuatif, yang artinya tiap bulannya selalu mengalami naik turun jumlah kunjungan.Kenaikan yang signifikan terjadi di setiap akhir tahun dimana hotel sendiri selalu mengadakan paket menginap. Mengacu terhadap hasil wawancara yang dilakukan terhadap target yang diterapkan oleh hotel ini menunjukkan bahwa selama 1 tahun terakhir hotel ini belum mampu mencapai target yang diterapkan hanya mampu mencapai angka $54.5 \%$ selama 1 tahun, memiliki selisih kurang lebih $11 \%$ dari target yang ditetapkan.

\section{B. Perumusan Masalah}

Berdasarkan dari latar belakang masalah seperti yang telah diuraikan diatas,Perumusan masalah sebagai berikut :

1. Apakah terdapat pengaruh kualitas pelayanan terhadap kepuasan pengunjung Hotle Risen Kedaton Bogor?

2. Apakah terdapat pengaruh kualitas pelayanan terhadap loyalitas pengunjung Hotel Rizen Kedaton Bogor?

3. Apakah terdapat pengaruh kepuasan pengunjung terhadap loyalitas pengunjung Hotel Rizen Kedaton Bogor?

\section{Tujuan Penelitian}

Tujuan yang hendak dicapai dalam penelitian ini adalah :

1. Untuk mengetahui apakah terdapat pengaruh kualitas pelayanan terhadap kepuasan pengunjung Hotle Risen Kedaton Bogor

2. Untuk mengetahui apakah terdapat pengaruh kualitas pelayana terhadap loyalitas pengunjung Hotel Rizen Kedaton Bogor 
3. Untuk mengetahui apakah terdapat pengaruh kepuasan pengunjung terhadap loyalitas pengunjung Hotel Rizen Kedaton Bogor

\section{Landasan Teori}

Manajemen merupakan ilmu dan seni mengatur proses pemanfaatan sumber daya manusia dan sumber-sumber lainnya secara efektif dan efisien untuk mencapai suatu tujuan tertentu. Malayu S.P Hasibuan (2014:1) Kotler dan Amstrong (2012:5) mendefinisikan tentang pemasaran: "Marketing as the process by which companies create value for customers and build strong customers relatioship in order to capture value from customers in return". Dimana pengertian tersebut adalah Pemasaran sebagai proses dimana perusahaan menciptakan nilai bagi pelanggan dan membangun pelanggan yang kuat relatioship untuk menangkap nilai dari pelanggan sebagai imbalan.

Secara ringkas definisi manajemen pemasaran yang disampaikan tersebut menyatakan bahwa : Manajemen pemasaran adalah merencanakan , pengerahan dan pengawasan seluruh kegiatan pemasaran perusahaan ataupun bagian dari perusahaan.

Kotler dalam Lupiyoadi (2014:7) "kualitas pelayanan adalah setiap tindakan atau kegiatan yang dapat ditawarkan oleh satu pihak kepada pihak lain, pada dasarnya tidak berwujud dan tidak mengakibatkan perpindahan kepemilikan apapun. Produksi jasa mungkin berkaitan dengan produk fisik atau tidak.

Kepuasan konsumen adalah tingkat perasaan dimana seseorang menyatakan hasil perbandingan atas kinerja produk jasa yang diterima dengan yang diharapkan, Kotler dalam Lupiyoadi (2014:228). Sedangakn menurut Kotler yang dikutip kembali oleh Fandy Tjiptono (2012:312) kepuasan konsumen adalah tingkat perasaan seseorang setelah membandingkan kinerja (atau hasil) yang ia persepsikan dibandingkan dengan harapannya. Terdapat beberapa hal yang mempengaruhi kepuasan pengunjung diantaranya menurut Lupiyoadi (2001:158) dalam jurnal Simon (2015) yaitu kualitas produk, emosional, harga, biaya dan kemudahan.

Loyalitas pengunjung merupakan hal yang penting dalam suatu perusahaan karena mempertahankan pengunjung berarti meningkatkan keuangan serta memeperthankan keberlangsungan hidup hotel sehingga tidak heran apabila suatu perusahan berusaha kerasa menjaga hubungan baik dan mempertahankan pengunjung nya.Adapun yang mempengaruhi loyalitas pengunjung menurut Griffin (2003:113)) dalam Nindia (2017:7) adalah Membeli ulang, Keamanan, Kenyamanan, Tidak pindah ke merk lain, Merekomendasikan pada perusahaan lain.

Hipotesis merupakn jawaban sementara atas masalah yang akan diteliti, dalam penelitian ini hipotesis dirumuskan sebagai berikut:

$\mathrm{H}_{1}$ : Terdapat pengaruh kualitas pelayanan terhadap kepuasan pengunjung Hotel Rizen Kedaton Bogor

H2 : Terdapat pengaruh kualitas pelayanan terhadap loyalitas pengunjung Hotel Rizen Kedaton Bogor 
H3 : Terdapat pengaruh kepuasan terhadap loyalitas pengunjung Hotel Rizen Kedaton Bogor

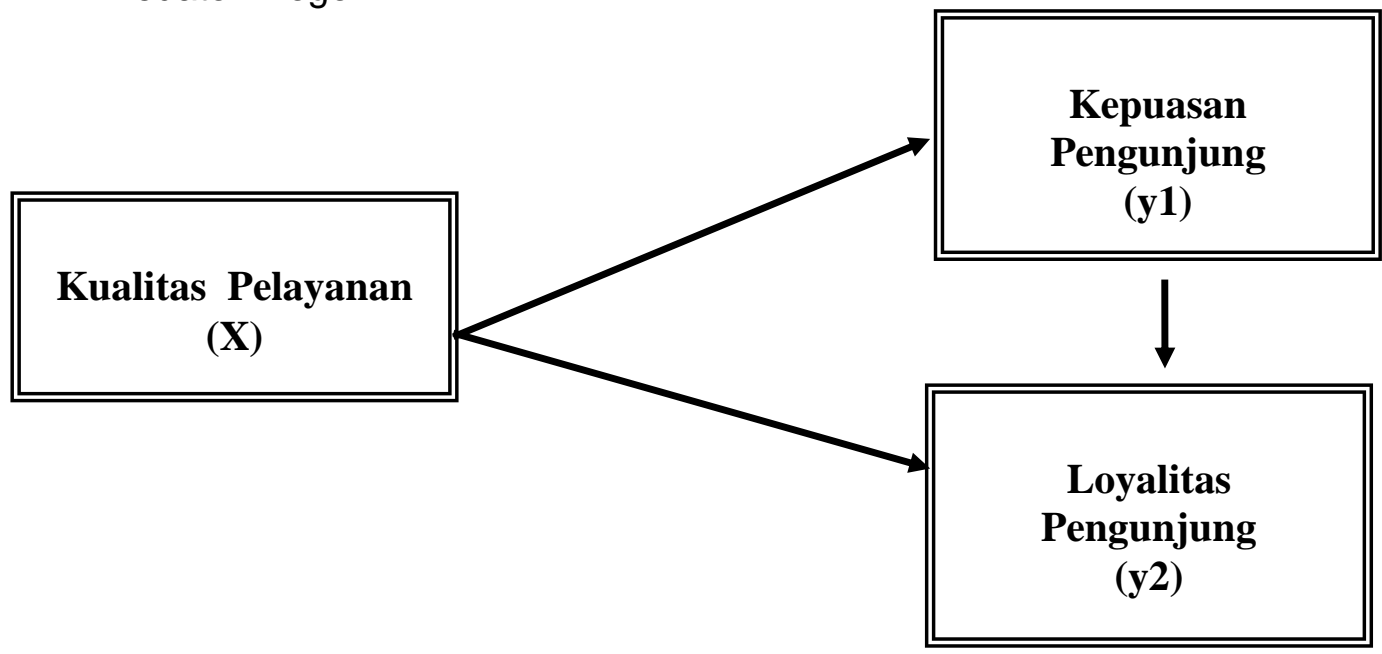

Gambar 1.2 Kerangak Berpikir

\section{E. Metodologi}

Penelitian ini dilakukan pada pengunjung Hotel Rizen Kedaton Bogor yang beralamat jalan Lodaya Desa Bojong Honje, Sukaraja Gunung Geulis, Jawa Barat Tlp. 0821-1149-6007.Adapun populasi dalam penelitian ini adalah pengunjung hotel yang sedang berkunjung dan menginap di hotel Rizen Kedaton, dima jumlah Populasi adalah Tamu yang berkujung dari Bulan Januari sampai dengan Agustus 2016 yaitu sebanyak 17.457. Sedangakan teknik sampling yang di gunakan ialah purposive sampling Dengan mengunakan rumus Slovin dengan tingakt error sebar 10\% maka diperoleh sampel 100 Pengunjung.

Jenis Penelitian ini adalah deskriptif asosiatif yang mengungkapkan secara fakta sejauh mana hubungan variabel kualitas pelayanan (X) terhadap variabel kepuasan pengunjung ( $\mathrm{y} 1$ ) dan loyalitas pengunjung (y2) serta kepuaan pengunjung (y) terhadap lyalitas pengunjung (y2).

Metode pengumpulan data yang penulis gunakan untuk penulisan skripsi ini adalah melalui studi pustaka (library research) dan studi lapangan (field research).Untuk memperoleh data yang relevan, akurat dan reliable dalam penelitian ini menggunakan dua macam sumber data yaitu sumber primer dan sumber sekunder.

\section{F. Hasil Penelitian \\ Hasil Analisis Deskriptif}

$$
\mathrm{P}=\frac{\text { Rentang }}{\text { BanyakKelas }}
$$

Dimana:

$$
\begin{array}{ll}
\text { P } & \text { : Panjang kelas interval } \\
\text { Rentang } & \text { : Data terbesar - data terkecil }
\end{array}
$$


Banyak kelas : 5

Jadi panjang kelas interval sebagai berikut: $P=\frac{5-1}{5}=0,8$

Dengan demikian kategori skala dapat ditentukan sebagai berikut :

1,00-1,79 : Sangat Tidak Baik

1,80-2,59: Kurang Baik

2,60 - 3,39: Cukup Baik

3,40 - 4,19: Baik

4,20 - 5,00: Sangat Baik

a. Deskripsi Kualitas Pelayanan Hotel Rizen Kedaton Bogor

Tabel 4.3

Deskripsi Variabel Kualitas Pelayanan

\begin{tabular}{|c|c|c|c|c|c|c|c|c|c|}
\hline \multirow{2}{*}{$\begin{array}{l}\mathrm{N} \\
\mathrm{O}\end{array}$} & \multirow[t]{2}{*}{ Pertanyaan } & \multicolumn{5}{|c|}{ Tingkat Persetujuan } & \multirow[t]{2}{*}{ Skor } & \multirow{2}{*}{$\begin{array}{l}\text { Rata- } \\
\text { rata }\end{array}$} & \multirow[t]{2}{*}{ Ket } \\
\hline & & SB & $B$ & $\mathrm{~KB}$ & TB & $\begin{array}{c}\text { ST } \\
\text { B }\end{array}$ & & & \\
\hline \multicolumn{10}{|c|}{ Kehandalan } \\
\hline 1 & $\begin{array}{l}\text { Karyawan } \\
\text { hotel } \\
\text { memberikan } \\
\text { pelayanan } \\
\text { yang } \\
\text { maksimal }\end{array}$ & 70 & 120 & 120 & 28 & 2 & 340 & 3,40 & BAIK \\
\hline 2 & $\begin{array}{l}\text { Kemauan dan } \\
\text { kejujuran } \\
\text { karyawan } \\
\text { hotel dalam } \\
\text { melayani } \\
\text { pengunjung }\end{array}$ & 50 & 172 & 123 & 12 & 0 & 357 & 3,57 & BAIK \\
\hline \multicolumn{10}{|c|}{ Empati } \\
\hline 3 & $\begin{array}{l}\text { Karyawan } \\
\text { hotel mampu } \\
\text { menjalin } \\
\text { hubungan baik } \\
\text { dengan } \\
\text { pengunjung } \\
\text { Hotel }\end{array}$ & 50 & 156 & 123 & 20 & 0 & 349 & 3,49 & BAIK \\
\hline 4 & $\begin{array}{l}\text { Karyawan } \\
\text { hotel mampu } \\
\text { melayani dan } \\
\text { berkomunikasi } \\
\text { dengan baik } \\
\text { dengan } \\
\text { pengunjung } \\
\text { hotel }\end{array}$ & 55 & 184 & 93 & 20 & 2 & 354 & 3,54 & BAIK \\
\hline
\end{tabular}


ISSN No. (PRINT) 2598-0823, (ONLINE) 2598-2893

\begin{tabular}{|c|c|c|c|c|c|c|c|c|c|}
\hline \multicolumn{10}{|c|}{ Daya tanggap } \\
\hline 5 & $\begin{array}{l}\text { Karyawan } \\
\text { hotel } \\
\text { menangani } \\
\text { masalah atau } \\
\text { keluhan } \\
\text { pengunjung } \\
\text { dengan cepat } \\
\text { dan tanggap }\end{array}$ & 95 & 120 & 51 & 46 & 11 & 323 & 3,23 & $\begin{array}{l}\text { CUKU } \\
\text { P BAIK }\end{array}$ \\
\hline 6 & $\begin{array}{l}\text { Karyawan } \\
\text { hotel dapat } \\
\text { merespon } \\
\text { permintaan } \\
\text { dan kebutuhan } \\
\text { pengunjung } \\
\text { secara cepat } \\
\text { dan tanggap }\end{array}$ & 80 & 148 & 48 & 36 & 13 & 325 & 3,25 & $\begin{array}{l}\text { CUKU } \\
\text { P BAIK }\end{array}$ \\
\hline \multicolumn{10}{|c|}{ Jaminan } \\
\hline 7 & $\begin{array}{l}\text { Karyawan } \\
\text { hotel mampu } \\
\text { menjalin } \\
\text { hubungan baik } \\
\text { dengan } \\
\text { pengunjung } \\
\text { hotel }\end{array}$ & 40 & 200 & 87 & 26 & 0 & 353 & 3,53 & BAIK \\
\hline 8 & $\begin{array}{l}\text { Karyawan } \\
\text { hotel } \\
\text { memahami } \\
\text { dengan baik } \\
\text { kebutuhan } \\
\text { para } \\
\text { pengunjung } \\
\text { hotel }\end{array}$ & 70 & 148 & 45 & 38 & 15 & 316 & 3,16 & $\begin{array}{l}\text { CUKU } \\
\text { P BAIK }\end{array}$ \\
\hline \multicolumn{10}{|c|}{ Bukti langsung } \\
\hline 9 & $\begin{array}{l}\text { Hotel rizen } \\
\text { kedaton } \\
\text { memiliki } \\
\text { interior kamar } \\
\text { yang lengkap, } \\
\text { nyaman, } \\
\text { bersih dan } \\
\text { tertata dengan } \\
\text { baik }\end{array}$ & 60 & 172 & 99 & 24 & 0 & 355 & 3,55 & BAIK \\
\hline 10 & $\begin{array}{l}\text { Hotel Rizen } \\
\text { Kedaton }\end{array}$ & 70 & 136 & 87 & 38 & 4 & 335 & 3,35 & $\begin{array}{l}\text { CUKU } \\
\text { P BAIK }\end{array}$ \\
\hline
\end{tabular}

Vol. 1, No.2 / Januari 2018 


\begin{tabular}{|c|c|c|c|c|c|c|c|c|}
\hline $\begin{array}{l}\text { Memiliki } \\
\text { Karyawan } \\
\text { Berpenampi } \\
\mathrm{n} \quad \mathrm{Ra} \\
\text { Bersih,Dan } \\
\text { Menarik }\end{array}$ & & & & & & & & \\
\hline Jumlah & $\begin{array}{c}64 \\
0 \\
\end{array}$ & 1556 & 876 & 288 & 47 & 3407 & $\begin{array}{c}34,0 \\
7\end{array}$ & \multirow{2}{*}{ BAIK } \\
\hline Persentase & 6,4 & $\begin{array}{c}15,5 \\
6\end{array}$ & $\begin{array}{c}8,7 \\
6\end{array}$ & $\begin{array}{c}2,8 \\
8\end{array}$ & $\begin{array}{c}0,4 \\
7\end{array}$ & $\begin{array}{c}34,0 \\
7\end{array}$ & 3,41 & \\
\hline
\end{tabular}

\section{Sumber : Data hasil kuesioner (2017)}

Berdasarkan data tabel di atas, rata-rata skor kualitas pelayanan sebesar 3,41masuk pada interval 3,40-4,19 dengan interpretasi baik yang artinya pengunjung mempunyai persepsi yang Baik terhadap kualitas pelayanan yang diberikan oleh Hotel Rizen Kedaton. Dan hal ini di buktikan dari jawaban pengunjung dari Skor tertinggi yaitu 3,57 pada Indikator "Kehandalan" dimana karyawan memiliki kemauan dan kejujuran untuk melayani pengunjung yang dating ke hotel, namun di sisi lain pihak Hotel Rizen Kedaton harus lebih meningkatkan kualitas pelayanan yang diberikan karena masih terdapat skor rendah yaitu 3,16 pada indicator "Jaminan"

\section{b. Deskripsi Kepuasan Pengunjung Hotel Rizen Kedaton}

Tabel 4.4

Deskripsi Variabel Kepuasan Pengunjung

\begin{tabular}{|c|c|c|c|c|c|c|c|c|c|}
\hline \multirow{2}{*}{ No } & \multirow{2}{*}{ Pertanyaan } & \multicolumn{5}{|c|}{ Tingkat Persetujuan } & \multirow[t]{2}{*}{ Skor } & \multirow{2}{*}{$\begin{array}{l}\text { Rata- } \\
\text { rata }\end{array}$} & \multirow[t]{2}{*}{ ket } \\
\hline & & $\mathrm{SP}$ & $P$ & KP & TP & STP & & & \\
\hline \multicolumn{10}{|c|}{ Kualitas dari fasilitas } \\
\hline 1 & $\begin{array}{l}\text { Tempat tidur } \\
\text { yang } \\
\text { disediakan } \\
\text { oleh hotel } \\
\text { memberikan } \\
\text { kenyaman } \\
\text { pada } \\
\text { pengunjung }\end{array}$ & 110 & 204 & 72 & 6 & 0 & 392 & 3,92 & BAIK \\
\hline 2 & $\begin{array}{l}\text { Tedapat } \\
\text { sarana parkir } \\
\text { yang luas dan } \\
\text { adanya } \\
\text { petugas parkir } \\
\text { yang selalu } \\
\text { membantu } \\
\end{array}$ & 120 & 212 & 54 & 6 & 2 & 394 & 3,94 & BAIK \\
\hline \multicolumn{10}{|c|}{ Perhatian terhadap pengunjung } \\
\hline 3 & $\begin{array}{l}\text { Karyawan } \\
\text { hotel ramah }\end{array}$ & 60 & 200 & 54 & 38 & 1 & 353 & 3,53 & BAIK \\
\hline
\end{tabular}




\begin{tabular}{|c|c|c|c|c|c|c|c|c|c|}
\hline & $\begin{array}{l}\text { dalam } \\
\text { meberikan } \\
\text { informasi } \\
\text { kepada } \\
\text { pengunjung } \\
\text { yang datang }\end{array}$ & & & & & & & & \\
\hline 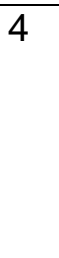 & $\begin{array}{l}\text { Karyawan } \\
\text { hotel yang } \\
\text { tulus dalam } \\
\text { melayani } \\
\text { pengunjung }\end{array}$ & 75 & 148 & 66 & 34 & 9 & 332 & 3,32 & $\begin{array}{l}\text { CUKUP } \\
\text { BAIK }\end{array}$ \\
\hline \multicolumn{10}{|c|}{ Membantu pengunjung } \\
\hline 5 & $\begin{array}{l}\text { Karyawan } \\
\text { hotel cepat } \\
\text { dalam } \\
\text { melayani } \\
\text { pengunjung }\end{array}$ & 65 & 160 & 84 & 24 & 7 & 340 & 3,40 & BAIK \\
\hline 6 & $\begin{array}{l}\text { Karyawan } \\
\text { hotel selalu } \\
\text { ada disaat } \\
\text { pengunjung } \\
\text { butuhkan }\end{array}$ & 60 & 200 & 54 & 38 & 1 & 353 & 3,53 & BAIK \\
\hline \multicolumn{10}{|c|}{ Sarana yang dimiliki } \\
\hline 7 & $\begin{array}{l}\text { Adanya kolam } \\
\text { renang, fitnes, } \\
\text { convention, } \\
\text { dan spa serta } \\
\text { outlet food \& } \\
\text { baverage yang } \\
\text { memadai }\end{array}$ & 75 & 148 & 66 & 34 & 9 & 332 & 3,32 & $\begin{array}{l}\text { CUKUP } \\
\text { BAIK }\end{array}$ \\
\hline 8 & \begin{tabular}{l}
\multicolumn{3}{l}{ Tersedianya } \\
AC dan \\
Saluran TV \\
dari berbagai \\
acara
\end{tabular} & 65 & 160 & 84 & 24 & 7 & 340 & 3,40 & BAIK \\
\hline \multicolumn{10}{|c|}{ Kenyaman dan penampilan } \\
\hline 9 & $\begin{array}{l}\text { Keadaan } \\
\text { kamar sesuai } \\
\text { dengan yang } \\
\text { diinformasikan } \\
\text { oleh petugas } \\
\text { front office }\end{array}$ & 80 & 116 & 78 & 38 & 9 & 321 & 3,21 & $\begin{array}{c}\text { CUKUP } \\
\text { BAIK }\end{array}$ \\
\hline 10 & $\begin{array}{l}\text { Hotel yang } \\
\text { selalu Nampak } \\
\text { bersih dan rapi }\end{array}$ & 75 & 128 & 81 & 34 & 7 & 325 & 3,25 & $\begin{array}{l}\text { CUKUP } \\
\text { BAIK }\end{array}$ \\
\hline
\end{tabular}

Vol. 1, No.2 / Januari 2018 


\begin{tabular}{|c|c|c|c|c|c|c|c|c|}
\hline Jumlah & 785 & 1676 & 693 & 276 & 52 & 3482 & 34,82 & \multirow{2}{*}{ BAlK } \\
\cline { 1 - 6 } Persentase & 7,85 & 16,76 & 6,93 & 2,76 & 0,52 & 34,82 & 3,48 & \\
\hline
\end{tabular}

Sumber : Data hasil kuesioner (2017)

Berdasarkan data tabel 4.4 di atas, rata-rata skor kepuasan pengunjung sebesar 3,48 masuk pada interval 3,40-4,19 dengan interpretasi Baikyang artinya pengunjung mempunyai persepsi puas terhadap kualitas pelayanan sudah diberikan Hotel Rizen Kedaton. Dan hal ini di buktikan dari jawaban pengunjung dari Skor tertinggi yaitu 3,94 pada Indikator "Kualitas dan Fasilitas" dimana sarana parkir yang luas dan adanya petugas parkir yang selalu membantu, namun di sisi lain pihak Hotel Rizen Kedaton harus lebih meningkatkan kepuasan pengunjung karena masih tersapat skor rendah yaitu 3,21 pada indikator "Kenyamanan

\section{c. Deskripsi Loyalitas Pengunjung Pada Hotel Rizen Kedaton Bogor} Tabel 4.5

Deskripsi Variabel Loyalitas Pengunjung

\begin{tabular}{|c|c|c|c|c|c|c|c|c|c|}
\hline $\begin{array}{l}\mathrm{N} \\
\mathrm{O}\end{array}$ & Butir Pernyataan & SB & B & $\mathrm{KB}$ & TB & STB & Skor & $\begin{array}{l}\text { Rat- } \\
\text { rata }\end{array}$ & Ket \\
\hline \multicolumn{10}{|c|}{ Kesetian } \\
\hline 1 & $\begin{array}{l}\text { Saya akan kembali } \\
\text { menggunakan jasa } \\
\text { penginapan di } \\
\text { Hotel Rizen } \\
\text { Kedaton Bogor }\end{array}$ & 50 & 136 & 93 & 34 & 8 & 321 & 3,21 & $\begin{array}{l}\text { CUKU } \\
\text { P BAIK }\end{array}$ \\
\hline 2 & $\begin{array}{lr}\text { Saya } & \text { akan } \\
\text { melakukan } & \\
\text { kunjungan rutin } \\
\text { setiap liburan ke } \\
\text { Hotel rizen } \\
\text { Kedaton } & \\
\end{array}$ & 35 & 164 & 66 & 32 & 14 & 311 & 3,11 & $\begin{array}{l}\text { CUKU } \\
\text { P BAIK }\end{array}$ \\
\hline 3 & 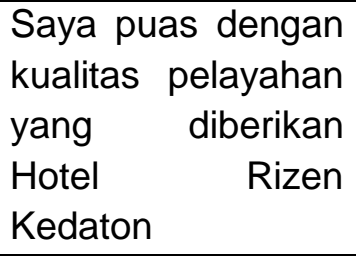 & 60 & 144 & 63 & 40 & 11 & 318 & 3,18 & $\begin{array}{l}\text { CUKU } \\
\text { P BAIK }\end{array}$ \\
\hline \multicolumn{10}{|c|}{ Ketahanan } \\
\hline 4 & $\begin{array}{l}\text { Saya akan terus } \\
\text { menggunakan jasa } \\
\text { penginapan Hotel } \\
\text { Rizen Kedaton }\end{array}$ & 60 & 168 & 78 & 28 & 6 & 340 & 3,40 & BAIK \\
\hline 5 & $\begin{array}{l}\text { Saya tidak tertarik } \\
\text { dengan dengan } \\
\text { Hotel yang berada } \\
\text { di sektitar Rizen } \\
\text { Kedaton Bogor }\end{array}$ & 100 & 172 & 69 & 14 & 7 & 362 & 3,62 & BAIK \\
\hline
\end{tabular}




\begin{tabular}{|c|c|c|c|c|c|c|c|c|c|}
\hline 6 & $\begin{array}{l}\text { Saya tertarik untuk } \\
\text { menginap di Hotel } \\
\text { Rizen Kedaton }\end{array}$ & 100 & 152 & 90 & 24 & 0 & 366 & 3,66 & BAIK \\
\hline \multicolumn{10}{|c|}{ Merefrensikan } \\
\hline 7 & $\begin{array}{lr}\text { Saya } & \text { mendapat } \\
\text { informasi } & \text { tentang } \\
\text { Hotel } & \text { Rizen } \\
\text { Kedaton } & \text { dari } \\
\text { teman saya } & \end{array}$ & 100 & 108 & 90 & 38 & 4 & 340 & 3,40 & BAIK \\
\hline 8 & 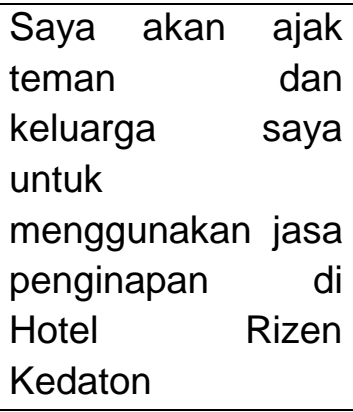 & 125 & 140 & 72 & 12 & 10 & 359 & 3,59 & BAIK \\
\hline 9 & $\begin{array}{l}\text { Saya } \\
\text { merekomendasika } \\
\mathrm{n} \text { Hotel Rizen } \\
\text { Kedaton di tempat } \\
\text { kerja saya sebagai } \\
\text { tempat penginapan }\end{array}$ & 100 & 204 & 78 & 6 & 0 & 388 & 3,88 & BAIK \\
\hline 10 & $\begin{array}{l}\text { Saya akan } \\
\text { memberitahukan } \\
\text { rasa puas saya di } \\
\text { media sosial }\end{array}$ & 105 & 128 & 60 & 8 & 2 & 303 & 3,03 & $\begin{array}{l}\text { CUKU } \\
\text { P BAIK }\end{array}$ \\
\hline & Total & 835 & 1516 & 759 & 236 & 62 & 3408 & $\begin{array}{c}34,0 \\
8\end{array}$ & BAIK \\
\hline & Persentase & $\begin{array}{c}8,3 \\
5\end{array}$ & $\begin{array}{c}15,1 \\
6\end{array}$ & $\begin{array}{c}7,5 \\
9\end{array}$ & 2,36 & 0,62 & $\begin{array}{c}34,0 \\
8\end{array}$ & 3,41 & \\
\hline
\end{tabular}

Sumber : Data hasil kuesioner (2017)

Berdasarkan data tabel di atas, rata-rata skor loyalitas pengunjung sebesar 3,41 masuk pada interval 3,40-4,19 dengan interpretasi Baikyang artinya responden mempunyai persepsi bahwa loyalitas pengunjuung Hotel Rizen Kedaton adalah baik. Dan hal ini di buktikan dari jawaban pengunjung dari Skor tertinggi yaitu 3,88 pada Indikator "Merefrensikan" dimana mayoritas pengunjung merekomendasikan Hotel Rizen Kedaton di tempat mereka bekerja baik tempat untk Gathering atau liburan biasa namun di sisi lain masih terdapat skor rendah 3,08 pada idnikator "Merefrensikan" dimana tidak semua pengunjung memberitahukan rasa puas mereka di media sosial hal ini karena tidak semua pengunjung juga menggunakan media sosial baik twitter mapun facebook. 
Hasil Uji Validitas

a. Uji Validitas Kualitas Pelayanan (X)

Tabel 4.6

Hasil Uji Validitas Variabel Kualitas Pelayanan

\begin{tabular}{|c|c|c|c|}
\hline No & R hitung & $\begin{array}{c}\mathrm{R} \\
\text { Tabel }\end{array}$ & Keputusan \\
\hline 1 & 0,330 & 0,300 & Valid \\
\hline 2 & 0,484 & 0,300 & Valid \\
\hline 3 & 0,384 & 0,300 & Valid \\
\hline 4 & 0,408 & 0,300 & Valid \\
\hline 5 & 0,798 & 0,300 & Valid \\
\hline 6 & 0,839 & 0,300 & Valid \\
\hline 7 & 0,685 & 0,300 & Valid \\
\hline 8 & 0,842 & 0,300 & Valid \\
\hline 9 & 0,684 & 0,300 & Valid \\
\hline 10 & 0,765 & 0,300 & Valid \\
\hline
\end{tabular}

Sumber : Hasil uji validitas data primer dengan SPSS

Berdasarkan hasil analisis di dapat nilai untuk item pernyatan 8 mendapat skor validitas tertinggi yaitu 0,842 dan item pernyataan 1 mendapat skor terendah yaitu 0,330. Namun secara keseluruhan instrument dikatakan valid karena nilia $r$ hitung $>r$ tabel.

b. Uji Validitas Variabel Kepuasan Pengunjung (y1)

Tabel 4.7

Hasil Uji Validitas Variabel Kepuasan Pengunjung

\begin{tabular}{|c|c|c|c|}
\hline No & R hitung & $\begin{array}{c}\mathrm{R} \\
\text { Tabel }\end{array}$ & Keputusan \\
\hline 1 & 0,544 & 0,300 & Valid \\
\hline 2 & 0,524 & 0,300 & Valid \\
\hline 3 & 0,712 & 0,300 & Valid \\
\hline 4 & 0,809 & 0,300 & Valid \\
\hline 5 & 0,794 & 0,300 & Valid \\
\hline 6 & 0,712 & 0,300 & Valid \\
\hline 7 & 0,809 & 0,300 & Valid \\
\hline 8 & 0,794 & 0,300 & Valid \\
\hline 9 & 0,799 & 0,300 & Valid \\
\hline 10 & 0,785 & 0,300 & Valid \\
\hline
\end{tabular}

Sumber : Hasil uji validitas data primer dengan SPSS

Keseluruhan variabel penetapan harga mendapat nilai rhitung > rtabel, dapat disimpulkan bahwa semua butir instrumen tersebut valid.

c. Uji Validitas Variabel Loyalitas pengunjung (y2)

Setelah dilakukan pengujian menggunakan SPSS 21 maka didapatkan hasilnya sebagai berikut :

Tabel 4.8 
Hasil Uji Validitas Variabel Loyalitas Pengunjung

\begin{tabular}{|c|c|c|c|}
\hline No & R hitung & R Tabel & Keputusan \\
\hline 1 & 0,829 & 0,300 & Valid \\
\hline 2 & 0,786 & 0,300 & Valid \\
\hline 3 & 0,799 & 0,300 & Valid \\
\hline 4 & 0,763 & 0,300 & Valid \\
\hline 5 & 0,777 & 0,300 & Valid \\
\hline 6 & 0,821 & 0,300 & Valid \\
\hline 7 & 0,840 & 0,300 & Valid \\
\hline 8 & 0,773 & 0,300 & Valid \\
\hline 9 & 0,619 & 0,300 & Valid \\
\hline 10 & 0,606 & 0,300 & Valid \\
\hline
\end{tabular}

Sumber : Hasil uji validitas data primer dengan SPSS

Dari tabel diatas dapat dilihat nilai hasil uji validitas, nilai ini kemudian kita bandingkan dengan nilai $r$ tabel, $r$ tabel dicari pada signifikasi 0,05didapat $r$ tabel sebesar 0,300 (Sugiyono, 2013:182). Secara keseluruhan nilai rhitung > rtabel maka dapat disimpulkan bahwa semua butir instrumen tersebut valid.

\section{Hasil Uji Reliabilitas}

Pengujian reliabilitas pada penelitian ini dilakukan dengan menggunakan metode Alpha-Cronbach dengan menggunakan aplikasi SPSS 22. Setelah dilakukanpengujian menggunakan SPSS 22 maka didapatkan hasilnya sebagai berikut :

Tabel 4.9

Hasil Uji Reliabilitas

\begin{tabular}{|c|c|c|c|}
\hline & & & \\
Variabel & Alpha Cronbach's & r tabel & Keterangan \\
\hline $\mathrm{X}$ & 0,837 & 0,600 & Reliabel \\
\hline $\mathrm{Y} 1$ & 0,905 & 0,600 & Reliabel \\
\hline $\mathrm{Y} 2$ & 0,920 & 0,600 & Reliabel \\
\hline
\end{tabular}

\section{Sumber : Data Primer 2017}

\section{Analisis Regresi Linear Sederhana}

a. Analsis Regresi Liner Sederhana Kualitas Pelayanan Terhadap Kepuasan Pengunjung

Tujuan analisis regresi linier sederhan adalah untuk mengukur intensitas hubungan antara dua variabel atau lebih dan membuat prediksi perkiraan nilai $Y$ atas $X$.

Tabel 4.10

Hasil Uji Regresi Linear Serderhana X-y1

Coefficients $^{a}$

\begin{tabular}{|c|c|c|c|c|c|c|}
\hline \multirow{3}{*}{\multicolumn{2}{|c|}{ 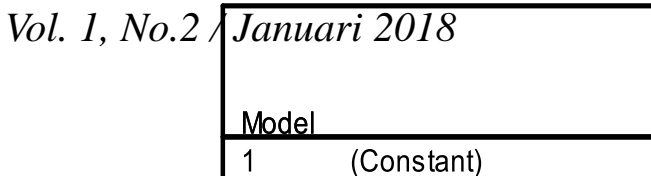 }} & \multicolumn{2}{|c|}{ Unstandardized Coefficients } & \multirow{2}{*}{$\begin{array}{c}\text { Standardized } \\
\text { Coefficients } \\
\text { Beta }\end{array}$} & \multirow[b]{2}{*}{$\mathrm{t}$} & \multirow[b]{2}{*}{ Sig. } \\
\hline & & $\mathrm{B}$ & Std. Error & & & \\
\hline & & 6.699 & 2.991 & & 2.240 & .027 \\
\hline & Kualitas Pelayanan $(\mathrm{X})$ & .826 & .086 & .695 & 9.582 & .000 \\
\hline
\end{tabular}




\section{Sumber: Output Spss 22, 2017}

Dari tabel tersebut diperoleh persamaan regresi linier sederhana sebagai berikut:

$Y 1=6,699+0,826 x$

Dimana:

$a=6,669$ merupakan nilai konstanta, jika kualitas pelayanan dianggap tidak ada maka nilai kepuasan pengunjung sebesar 6,699

b1 $=0,826$ koefisien regresi variabel kualitas pelayanan sebesar 0,826 artinya jika kualitas mengalami peningkatan satu-satuan maka kepuasan pengunjung mengalami peningkatan sebesar 0,826 dan koefisein regresi bernilai positif artinya terjadi hubungan positif antara kualitas pelayanan dengan kepuasan pengunjung dimana semakin meningkat kualitas pelayanan maka kepuasan pengunjung juga akan semakin meningkat.

b. Analsis Regresi Liner Sederhana Kualitas Pelayanan Terhadap Loyalitas Pengunjung

Berikut ini data hasil SPSS yang adalah sebagai berikut:

Tabel 4.11

Hasil Uji Regresi Linear Serderhana X-y2

Coefficients $^{\mathrm{a}}$

\begin{tabular}{|c|c|c|c|c|c|c|}
\hline \multirow[b]{2}{*}{ Model } & & \multicolumn{2}{|c|}{ Unstandardized Coefficients } & \multirow{2}{*}{$\begin{array}{c}\text { Standardized } \\
\text { Coefficients } \\
\text { Beta } \\
\end{array}$} & \multirow[b]{2}{*}{$t$} & \multirow[b]{2}{*}{ Sig. } \\
\hline & & B & Std. Error & & & \\
\hline 1 & (Constant) & 3.635 & 2.917 & & 1.246 & .216 \\
\hline & Kualitas Pelayanan $(X)$ & .918 & .084 & .741 & 10.918 & .000 \\
\hline
\end{tabular}

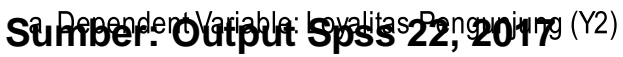

Dari tabel tersebut diperoleh persamaan regresi linier sederhana sebagai berikut:

$Y 1=3,635+0,918 x$

Dimana:

$a=3,635$ merupakan nilai konstanta, jika kualitas pelayanan dianggap tidak ada maka nilai loyalitas pengunjung sebesar 3,635

b1=0,918 koefisien regresi variabe kualitas pelayanan sebesar 0,918 artinya jika kualitas pelayanan mengalami peningkatan satusatuan maka kepuasan loyalitas pengunjung mengalami peningkatan sebsar 0,918 dan koefisein regresi bernialia positif artinya terjadi hubungan positif antara kualitas pelayanan dengan loyalitas pengunjung dimana semakin meningkat kualitas 
pelayanan maka loyalitas pengunjung juga akan semakin meningkat.

c. Analsis Regresi Liner Sederhana Kepuasan Pengunjung Terhadap Loyalitas Pengunjung

Berikut ini data hasil SPSS yang adalah sebagai berikut:

Tabel 4.12

Hasil Uji Regresi Linear Serderhana y1-y2

Coefficients $^{\mathrm{a}}$

\begin{tabular}{|c|c|c|c|c|c|c|}
\hline \multirow[b]{2}{*}{ Mode } & & \multicolumn{2}{|c|}{ Unstandardized Coefficients } & \multirow{2}{*}{$\begin{array}{c}\begin{array}{c}\text { Standardized } \\
\text { Coefficients }\end{array} \\
\text { Beta }\end{array}$} & \multirow[b]{2}{*}{ t } & \multirow[b]{2}{*}{ Sig. } \\
\hline & & B & Std. Error & & & \\
\hline & (Constant) & 4.124 & 2.000 & & 2.062 & .042 \\
\hline & $\begin{array}{l}\text { Kepuasan Pengunjung } \\
\text { (Y1) }\end{array}$ & .884 & .056 & .847 & 15.770 & .000 \\
\hline
\end{tabular}

a. Dependent Variable: Loyalitas Pengunjung (Y2)

\section{Sumber: Output Spss 22, 2017}

Dari tabel tersebut diperoleh persamaan regresi linier sederhana sebagai berikut:

$\mathrm{Y} 1=4,124+0,884$

Dimana:

$\mathrm{a}=$ 4,124 merupakan nilai konstanta, jika kepuasan pengunjung dianggap tidak ada maka nilai loyalitas pengunjung sebesar 4,124

b1=0,884 koefisien regresi variabe kepuasan pengunjung sebesar 0,884 artinya jika kepuasna pengunjung mengalami peningkatan satu-satuan maka loyalitas pengunjung mengalami peningkatan sebsar 0,884 dan koefisein regresi bernialia positif artinya terjadi hubungan positif antara kepuasan pengunjung dengan loyalitas pengunjung diman semakin meningkat kepuasan pengunjung maka loyalitas pengunjung juga akan semakin meningkat.

\section{Uji Koefisien Determinasi}

a. Koefisein Determinasi Kualitas Pelayanan Terhadap Kepuasan Pengunjung

Tabel 4.13

Hasil Uji Koefisien Determinasi X-y1

Model Summary

\begin{tabular}{|c|l|r|r|r|}
\hline Model & $\mathrm{R}$ & R Square & $\begin{array}{c}\text { Adjusted R } \\
\text { Square }\end{array}$ & $\begin{array}{c}\text { Std. Error of } \\
\text { the Estimate }\end{array}$ \\
\hline 1 & $.695^{\mathrm{a}}$ & .484 & .478 & 5.618 \\
\hline
\end{tabular}

a. Predictors: (Constant), Kualitas Pelayanan (X)

\section{Sumber: Output Spss 22, 2017}

Berdasarkan tabel diatas maka dapat diketahui nilai $r$ square adalah 0,484 hal iniberarti kualitas pelayanan mempunyai kontribusi secara bersama-sama sebesar $48,4 \%$ terhadap variabel kepuasan 
pengunjung. Sisanya $51,52 \%$ dipengaruh oleh factor lain yang tidak diteliti dalam penelitian ini.

b. Koefisein Determinasi Kualitas Pelayanan Terhadap Loyalitas Pengunjung

Tabel 4.14

Hasil Uji Koefisien Determinasi X-y2 Model Summary

\begin{tabular}{|c|c|r|r|r|}
\hline Model & $\mathrm{R}$ & $\mathrm{R}$ Square & $\begin{array}{c}\text { Adjusted R } \\
\text { Square }\end{array}$ & $\begin{array}{c}\text { Std. Error of } \\
\text { the Estimate }\end{array}$ \\
\hline 1 & $.741^{\mathrm{a}}$ & .549 & .544 & 5.479 \\
\hline
\end{tabular}

a. Predictors: (Constant), Kualitas Pelayanan (X)

Sumber: Output Spss 22, 2017

Berdasarkan tabel diatas maka dapat diketahui nilai $r$ square adalah 0,549 hal ini berarti kualitas pelayanan mempunyai kontribusi secara bersama-sama sebesar $54,9 \%$ terhadap variabel loyalitas pengunjung. Sisanya $45,1 \%$ dipengaruh oleh factor lain yang tidak diteliti dalam penelitian ini.

c. Koefisein Determinasi Kepuasan Pengunjung Terhadap Loyalitas Pengunjung

Tabel 4.15

Hasil Uji Koefisien Determinasi y1-y2 Model Summary

\begin{tabular}{|c|c|r|r|r|}
\hline Model & R & R Square & $\begin{array}{c}\text { Adjusted R } \\
\text { Square }\end{array}$ & $\begin{array}{c}\text { Std. Error of } \\
\text { the Estimate }\end{array}$ \\
\hline 1 & $.847^{a}$ & .717 & .714 & 4.337 \\
\hline
\end{tabular}

Sumber: Outpurt Sppss: 22,2017$)$ Kepuasan Pengunjung (Y1)

Berdasarkan tabel diatas maka dapat diketahui nilai $r$ square adalah 0,847 hal ini berarti kepuasan pengunjung mempunyai kontribusi secara bersama-sama sebesar $71,7 \%$ terhadap variabel loyalitas pengunjung. Sisanya $28,3 \%$ dipengaruh oleh factor lain yang tidak diteliti dalam penelitian ini.

\section{G Pembahasan}

\section{Variabel Kualitas Pelayanan Terhadap Kepuasan Pengunjung}

Berdasarkan data tabel 4.3, rata-rata skor kualitas pelayanan sebesar 3,41 masuk pada interval 3,40-4,19 dengan interpretasi baik yang artinya pengunjung mempunyai persepsi yang Baik terhadap kualitas pelayanan yang diberikan oleh Hotel Rizen Kedaton.

Berdasarkan hasil uji validitas pada tabel 4.6 semua pernyataan yang ada pada kuesioner dikatakan valid karena nilai $r$ hitung $>r$ tabel dimana instrument kuesioner no $1,0,330>0,300$ sesuai dengan pernytaan Sugiyono (2013:182).

Dan nilai reliabilitas pada tabel 4.8 meperoleh niliai $0,837>0,600$ sesuai dengan pertnyataan Sugiyono (2013:184) sehingg kuesioner yang ad dinyatakn reliabel untuk pengujian selanjutnya. 
Untuk nilai t hitung jika di lihat pada tabel 4.9 diperoleh nilai t hitung 9,582 > t tabel 1,985 dan sig < 0,05 maka kualitas pelayanan memiliki pengaruh positif dan signifikan terhadap kepuasan pengunjung Hotel Rizen Kedaton Bogor.

Untuk regsi linear sederhana diperoleh nilain y1=6,699+0,826 dimana a=6,669 merupakan nilai konstanta, jika kualitas pelayanan dianggap tidak ada maka nilai kepuasan pengunjung sebesar 6,699 dan b1=0,826 koefisien regresi variabel kualitas pelayanan sebesar 0,826 artinya jika kualitas mengalami peningkatan satu-satuan maka kepuasan pengunjung mengalami peningkatan sebesar 0,826 dan koefisein regresi bernilai positif artinya terjadi hubungan positif antara kualitas pelayanan dengan kepuasan pengunjung dimana semakin meningkat kualitas pelayanan maka kepuasan pengunjung juga akan semakin meningkat.

Berdasarkan tabel 4.13 maka dapat diketahui nilai $r$ square adalah 0,484 hal ini berarti kualitas pelayanan mempunyai kontribusi secara bersama-sama sebesar $48,4 \%$ terhadap variabel kepuasan pengunjung. Sisanya $51,52 \%$ dipengaruh oleh factor lain yang tidak diteliti dalam penelitian ini.

\section{Variabel Kualitas Pelayanan Terhadap Loyalitas Pengunjung}

Berdasarkan data tabel 4.4 di atas, rata-rata skor kepuasan pengunjung sebesar 3,48 masuk pada interval 3,40-4,19 dengan interpretasi Baik yang artinya pengunjung mempunyai persepsi puas terhadap kualitas pelayanan sudah diberikan Hotel Rizen Kedaton.

Berdasarkan hasil uji validitas pada tabel 4.7 semua pernyataan yang ada pada kuesioner dikatakan valid karena nilai $r$ hitung $>r$ tabel dimana instrument kuesioner no 1, 0,544 >0,300 sesuai dengan pernytaan Sugiyono (2013:182).

Dan nilai reliabilitas pada tabel 4.8 memperoleh niliai $0,905>0,600$ sesuai dengan pertnyataan Sugiyono (2013:184) sehingg kuesioner yang ad dinyatakn reliabel untuk pengujian selanjutnya.

Untuk nilai t hitung jika di lihat pada tabel 4.10 diperoleh nilai t hitung $10,918>$ t tabel 1,985 dan sig < 0,05 maka kualitas pelayanan memiliki pengaruh positif dan signifikan terhadap loyalitas pengunjung Hotel Rizen Kedaton Bogor.

Untuk regsi linear sederhana diperoleh $Y 1=3,635+0,918 x$ dimana $a=$ 3,635 merupakan nilai konstanta, jika kualitas pelayanan dianggap tidak ada maka nilai loyalitas pengunjung sebesar 3,635 dan b1=0,918 koefisien regresi variabe kualitas pelayanan sebesar 0,918 artinya jika kualitas pelayanan mengalami peningkatan satu-satuan maka kepuasan loyalitas pengunjung mengalami peningkatan sebsar 0,918 dan koefisein regresi bernialia positif artinya terjadi hubungan positif antara kualitas pelayanan dengan loyalitas pengunjung dimana semakin meningkat kualitas pelayanan maka loyalitas pengunjung juga akan semakin meningkat.

Berdasarkan tabel 4.14 maka dapat diketahui nilai $r$ square adalah 0,549 hal ini berarti kualitas pelayanan mempunyai kontribusi secara 
bersama-sama sebesar 54,9\% terhadap variabel loyalitas pengunjung. Sisanya $45,1 \%$ dipengaruh oleh factor lain yang tidak diteliti dalam penelitian ini.

3. Variabel Kepuasan Pengunjung Terhadap Loyalitas Pengunjung

Berdasarkan data tabel 4.5 di atas, rata-rata skor loyalitas pengunjung sebesar 3,41 masuk pada interval 3,40-4,19 dengan interpretasi Baik yang artinya responden mempunyai persepsi bahwa loyalitas pengunjuung Hotel Rizen Kedaton adalah baik.

Berdasarkan hasil uji validitas pada tabel 4.7 semua pernyataan yang ada pada kuesioner dikatakan valid karena nilai $r$ hitung $>r$ tabel dimana instrument kuesioner no 1, 0,829 >0,300 sesuai dengan pernytaan Sugiyono (2013:182).

Dan nilai reliabilitas pada tabel 4.9 memperoleh niliai $0,920>0,600$ sesuai dengan pertnyataan Sugiyono (2013:184) sehingga kuesioner yang ada dinyatakn reliabel untuk pengujian selanjutnya.

Untuk nilai t hitung jika di lihat pada tabel 4.12 diperoleh nilai t hitung $15,770>t$ tabel 1,985 dan sig < 0,05 maka kepuasan pengunjung memiliki pengaruh positif dan signifikan terhadap loyalitas pengunjung Hotel Rizen Kedaton Bogor.

Untuk regsi linear sederhana diperoleh $\mathrm{Y} 1=4,124+0,884$ dimana $\mathrm{a}=$ 4,124 merupakan nilai konstanta, jika kepuasan pengunjung dianggap tidak ada maka nilai loyalitas pengunjung sebesar 4,124 sedangan b1=0,884 koefisien regresi variabe kepuasan pengunjung sebesar 0,884 artinya jika kepuasna pengunjung mengalami peningkatan satu-satuan maka loyalitas pengunjung mengalami peningkatan sebsar 0,884 dan koefisein regresi bernialia positif artinya terjadi hubungan positif antara kepuasan pengunjung dengan loyalitas pengunjung diman semakin meningkat kepuasan pengunjung maka loyalitas pengunjung juga akan semakin meningkat.

Berdasarkan tabel 4.15 maka dapat diketahui nilai $r$ square adalah 0,847 hal ini berarti kepuasan pengunjung mempunyai kontribusi secara bersama-sama sebesar $71,7 \%$ terhadap variabel loyalitas pengunjung. Sisanya $28,3 \%$ dipengaruh oleh factor lain yang tidak diteliti dalam penelitian ini.

\section{H Kesimpulan}

Berdasarkan rumusan malasah diatas maka dapat ditarik kesimpulan berdasarkan hasil penelitian yang dibuat oleh penulis diantanyarnya adalah:

1. Sesuai dengan rumusan masalah maka terdapat pengaruh yang positif dan signikan dari kualitas pelayanan terhadap kepuasan pengunjung hal ini dilihat dari uji Hipotesis bahwa nilai t hitung 9,582> t tabel 1,985 dan sig $<0,05$.

2. Sesuai dengan rumusan masalah maka terdapat pengaruh yang positif dan signikan dari kualitas pelayanan terhadap loyalitas pengunjung hal ini dilihat dari uji Hipotesis bahwa nilai t hitung 10,918> t tabel 1,985 dan sig $<0,05$. 
3. Sesuai dengan rumusan masalah maka terdapat pengaruh yang positif dan signifikan dari kepuasan pengunjung terhadap loyalitas pengunjung hal ini dilihat dari $t$ hitung $15,770>t$ tabel 1,985 dan sig $<0,05$

\section{Daftar Pustaka}

Adiatma, Fajar, "Pengaruh Penetapan Harga Produk Terhadap Keputusan PembelianKonsumen" (Studi Pada Rumah Makan Soto Dan Sop Nanda Jalan Sei BlutuPasar Ix No.12 Medan), 2013.

Arikunto, Suharsimi. "Prosedur Penelitian, Suatu Pendekatan Praktik", Rineka Cipta, Jakarta, 2006.

Assauri, Sofjan, "Manajemen Pemasaran". Raja Grafindo Persada: Jakarta, 2014.Becherel, Lionel Vellas Francois. "Pemasaran Pariwisata Internasional". Yayasan OborIndonesia.Jakarta, 2008.

Ghozali, Imam, "Aplikasi Analisis Multivariate Dengan Spss". Cetakan keempat.Badan penerbit Universitas Diponegoro, Semarang, 2006. "Model Persamaan Struktural Konsep dan Aplikasi dengan ProgramAmos 16.0", Badan Penerbit UNDIP, Semarang, 2008.

Husein Umar. "Metode Penelitian untuk Skripsi dan Tesis Bisnis". PT Raja Grafindo Persada, Jakarta, 2008.

Istijanto, "Aplikasi Praktis Riset Pemasaran", Gramedia Pustaka Utama, Jakarta, 2009.

Kotler, Philip, “Manajemen Pemasaran”, Edisi 13. Erlangga. Jakarta, 2009.

"Manajemen Pemasaran Perspektif Asia", Buku Dua, Edisi Pertama, Andy, Yogyakarta, 2012'

Kotler, Philip \& Amstrong, Garry. "Prinsip-prinsip Pemasaran", Jilid 1, Erlangga, Jakarta, 2008.

\section{"Prinsip-prinsip Pemasara",}

Edisi13. Jilid1.Erlangga. Jakarta, 2012.

Kotler, Phillip dan Keller, Kevin Lane, "Manajemen Pemasaran”, Edisi 12 Jilid 2. Pengalih Bahasa Benyamin Molan. PT. Indeks. Jakarta, 2007 "Manajemen Pemasaran" Jilid 1, edisi Ketiga Belas,

Terjemahan Bob Sabran, MM, Penerbit Erlangga, Jakarta, 2009.

Lupiyoadi, Rambat, "Manajemen Pemasaran Jasa Teori dan Praktik", SalembaEmpat.

Jakarta, 2011.

Malhotra, N.K., "Riset Pemasaran", Edisi keempat, Jilid 1, PT Indeks, Jakart, 2009

Muhammad.S.SA." Pengaruh Kepemimpinan Terhadap Kepuasan Kerja Dan Kinerja Karyawan PT Bank Tbaungan Negara (Persero) Cabang Makasar". Skripsi.

Universitas Hasanudin. Makasar. 2015

Nur Indah S, Melia, "Statistik Deskriptif dan Induktif", Ed. I, Cet. I, Graha IImu, Yogyakarta, 2010. 
Natalia,Melisa, "Pengaruh Penetapan Harga Terhadap Keputusan PembelianKonsumen" (Studi Kasus Pada Hen's Salon Di Bandung), 2011.

Rambat Lupiyoadi dan A. Hamdani, "Manajemen Pemasaran jasa" edisi 2: Salemba Empat, Jakarta 2011.

Rosa Lesmana."Pengaruh Kelengkapan Produk dan Petepan Harga Terhadap Keputusan Pembelian Konsumen (Studi Kasus Pada Toko H. Uding Cisaukn Tangerang). Jurnal. Universitas Pamulang. 2017.

Safroni, Ladzi. "Manajemen dan Reformasi Pelayanan Publik dalam Konteks Birokrasilndonesia", Aditya Media Publishing, Surabaya 2012.

Schiffman, Kanuk. "Perilaku Konsumen". Edisi 7. PT. Indeks. Jakarta, 2008.

Simon E. "Penagruh Kualitas produk dan Penetapan Harga Terhadap Kepuasan Konsumen (Suatu Survey Pada Toko Boneka Angsaka Cijerah).Jurnal. Universitas Komputer Indonesia. 2014.

Sugiyono, "Metode Peneltian Kombinasi (Mixed Methods)", Alfabeta, Bandung, 2013.

, "Metode Penelitian Bisnis(Pendekatan Kuantitatif, Kualitatif, dan R\&D)".Alfabeta, Bandung, 2010.

Tjiptono, Fandy dan Gregorius Chandra, "Pemasaran Strategik", Andi. Yogyakarta,

2012. 